\title{
Investigation Effects of Lavenders Flowers Extracts on Catalase Activity and Some Microorganisms.
}

\author{
Ali Mohammed Abbed \\ Department of Chemistry, College of Science, Mustansiriyah University, Baghdad-Iraq. \\ Corresponding Author: alimaa1978@gmail.com
}

\begin{abstract}
The present study was proposed to examine one of the important herbal plant is known Lavender and study the interaction of its extracts with enzymatic oxidation reduction process and anti microorganism. The catalase assay in vitro was implied in this work. Lavender flower containing on essential oils has been many uses for disease treatment, this plant bring from the trading market in Iraq. The current study involved biological activity on two ways; alcoholic extract on enzymatic activity, other way hot water extract and alcoholic extract on four isolate of bacteria and one type fungi. (The weight of flower is equal to $1 \mathrm{gm} / 50 \mathrm{ml}$ for two extracts). The results of this study demonstrated effect of lavender to be activator agent of catalase enzymatic activity and $V_{\max }$ was calculated without and with extract that equal to $(88.6,208) \mathrm{Ku} / \mathrm{L}$ and $\mathrm{km}$ equal to $(53.5$, 72.4)mM respectively by Line weaver-Burk plot. The activation percentage was calculated by using different volume of Ethanolic extract, that maximum activation is recorded equal to $133.6 \%$ at substrate concentration $60 \mathrm{mM}$ and $100 \mu \mathrm{l}$ alcoholic extract. On the other hand their effects on microorganism obvious in the present study that showed not effect began.
\end{abstract}

[DOI: 10.22401/ANJS.22.1.08]

Keywords: Lavender, Catalase, Microorganism, Extract, Activation.

\section{Introduction}

The experiments carried out on the plant constituents effects, and uses belonged to the importance of these living objects materials therefore occupy upper class importance in the studies and investigations of the plant constituents as well as in our study catalytic of enzyme and antimicrobial, also plant extract with plant using for medications. The synthesis antimicrobial was used for a long time versus different infections for various living objects but the drawback is antimicrobial resistance and finally confer less effective treatment, [1]. Volatile compound obtained from plant extract in particularly essential oil which is defined as a secondary plant metabolite and used for many uses as cosmetics, pharmaceutical and chemotherapy, [2]. Lavender is a purple flower plant, widely distributed belonged to the family Lamiaceae and cultivated of South America, Europe and Asia; its important properties is very pleasant smell and bitter taste. This is used for insect bites, treatment of skin sores, rheumatic and nervous disorders, gastrointestinal, antiepileptic, diuretic, sedative, burn healing, antibacterial and antioxidant, [3,4]. Main constituents of lavender are essential oils of the most popular, when extracted from several species of this plant. There are four major class species of lavender named; Lavendula stoechas, Lavendiola intermedia, Lavendula latifolia and Lavendula angostifolia. The culture species in extensive to be a commercial is a Lavendula angostifolia which is used in this study, [5]. Lavender oil in primarily composed of sesqui terpenoids and terpenoids, but the most dominant constituents are linalool and linalyl acetate while camphor and 1,8cineole are composition of lavender in low to moderate, [6].

Catalase (CAT, $\quad \mathrm{H}_{2} \mathrm{O}_{2}: \quad \mathrm{H}_{2} \mathrm{O}_{2} \quad-$ oxidoreductase), EC (1.11.1.6) is one of the enzymes belonged to the $19^{\text {th }}$ century, when they are became one of the first sources adequate information about the behavior and nature of this enzyme. The discovery names of these enzymes due to its catalytic action on the hydrogen peroxide and catalyzes the decomposition of hydrogen peroxide to water and oxygen. The chemical structure of this enzyme is tetrameric proteinof $244 \mathrm{KDa}$, containing four subunit of $59.7 \mathrm{KDa}$. Each subunit containing 527 amino acids residues, one haem group namely $\mathrm{Fe}^{+3}$ protoporphyrine 5 which is tightly bound molecule of NADPH, 
$[7,8]$. Where two subunit from catalase a large structure tetramer have a huge density for NADPH, [9]. Catalase of human belonged to group of mono functional haem-containing catalase. The highest level of catalase is found in all living organisms and in mammals in the erythrocyte, liver and in the (saliva, kidney) occasionally which is located in the peroxisome of cells. It is protective enzyme nearly all animals cells, [10]. The investigation of catalase activity in various pathophysiological states in the oxidative stress case, because this enzyme protect the cells from oxidative stress, [11]. Increasing activity of catalase as clinical significance is moderately in fatty liver, acute alcoholic, cardiac circulatory failure and hepatitis, [12].

\section{Materials and methods}

\subsection{Lavender flowers extractions}

Lavender flowers were purchased from the trading market. This flower weighted (1gm) and macerated with $(50 \mathrm{ml})$ absolute Ethanol for ( 24 hours); then this mixture shaked and filtrated at two steps the first by medicinal lint and at the second step by filter paper, which was took and used to study on the enzymatic activity and microorganisms. On the other hand take the flowers $(1 \mathrm{gm})$ was put in $(50 \mathrm{ml})$ distilled water and heated for $1 / 2$ hour at boiling point then cooling with complete the volume to $(50 \mathrm{ml})$ distilled water and filtered with medicinal lint and filter paper but study applied on the microorganisms only; the filtrate which is obtained via absolute ethanol and heated distilled water was deep clear yellow and slightly clear yellow with respectively.

\subsection{Catalase activity}

Different concentrations $(\mathrm{mM})$ of $(1 \mathrm{ml})$ substrate hydrogen peroxide in $60 \mathrm{mM}$ The assay of catalase activity in optimum conditions; was take $200 \mu \mathrm{l}$ of serum to incubate of potassium phosphate buffer $(\mathrm{pH}=7.4)$ at $37 \mathrm{C}^{\circ}$ for 1 minute. In these conditions the unit enzyme decomposes $1 \mu \mathrm{mol}$ of hydrogen peroxide/1min. Then the enzymatic reaction was stopped via $1 \mathrm{ml}$ of 32 $\mathrm{mM}$ of ammonium molybdate, then the complex yellow color of produced complex read at $405 \mathrm{~nm}$ against blanks, and the activity was estimated as the following equation.
Catalase activity $(\mathrm{KU} / \mathrm{L})=\frac{\text { A sample }- \text { A blank } 1}{A \text { blank }-A \text { blank } 3} \times 271$

Blank 1 contained $1.0 \mathrm{~mL}$ of substrate, 1.0 $\mathrm{mL}$ molybdate and $200 \mu \mathrm{l}$ serum; Blank 2 contained $1.0 \mathrm{~mL}$ of substrate, $1.0 \mathrm{~mL}$ molybdate and $0.2 \mathrm{~mL}$ buffer; Blank 3 contained $1.2 \mathrm{~mL}$ of buffer, $1.0 \mathrm{~mL}$ molybdate and $0.2 \mathrm{~mL}$ buffer, [13]. Where this study was carried out on the sera of healthy human individuals in vitro.

\subsection{Estimation of the appropriate substrate concentration in the absence and presence of lavender extracts}

The procedure was carried out to calculate catalase activity by using different concentration of substrate in buffer solution $(20,30,40,50,60,70,80) \mathrm{mM}$ alone in the absence of extract. The optimum substrate concentration was estimated by plotting the relationship between the enzyme activities versus the substrate concentration values, this procedure applied also in the presence of extract by adding $100 \mu \mathrm{l}$ filtrate of $(1 \mathrm{gm} / 50 \mathrm{ml}$ absolute ethanol) lavender flower to the all different substrate concentrations to estimate $\left(\mathrm{Km}, \mathrm{V}_{\max }\right.$ and $\mathrm{V}_{\circ}$ ) by Lineweaver-Burk plot and Michalis Menton diagram.

\subsection{Studying the effect of extract volume on the enzymatic activity}

To investigation of the volume change effect of extract by using different volume from the stock $(1 \mathrm{gm} / 50 \mathrm{ml}$ absolute ethanol); $(10,25,50,75,100) \mu 1$, that is meaning study the effect of extract concentration on the enzymatic activity.

\subsection{Target organisms and agar disk diffusion test}

Microorganisms obtained from preservative and available bacteria dynasty in the laboratory of biology department, that included gram positive (Streptococcus) and gram negative (Bacilli, Salmonella typhi, Shegella) and this study else carried out on the fungi such as (Candida albicans). The components of media which was used in this study are different culture compounds such as Eozine methylene blue (EMB), nutrient agar and Muller Hinton agar to breed development of microorganisms, [14,15]. Biological activity of lavender was studied when extracted via 
absolute ethanol and hot water as another extract solvent. Disk diffusion test of lavender extracts was carried out on the cultured bacteria and fungi at $37^{\circ} \mathrm{C}$ in typical agar with add $100 \mu \mathrm{l}$ of extracts with $100 \mu \mathrm{l}$ of Ethanol absolute as a control for 24 hours.

\section{Results and discussions}

Herbal plants have been many advantages due to the multi uses, available in the trading market and have fewer side effects. Therefore considered more interest to evaluation of constituent's effects in biochemistry applications. The current study Included biological activity on two ways (1. Alcoholic extract on enzymatic activity 2. Alcoholic and hot water extracts on microorganisms as well as four isolate species with one type of fungi).

Enzymatic activity showed that the relationship between substrate concentration and the velocity of the enzymatic catalyzed reaction. This was studied in the absence and presence of Ethanolic extract with different concentrations of $\mathrm{H}_{2} \mathrm{O}_{2}$ as a substrate. The curves that obtained in the Fig.(1); demonstrated that the enzymatic activity is directly increased in proportional to substrate concentration without and with extract in the range (30-60) $\mathrm{mM}$ and (30-80) $\mathrm{mM}$ respectively. Under these conditions all the enzymes bound to substrate as a complex and the rate of reaction is maximum, [16], the increasing of enzymatic catalytic with extract may be lead to increasing of binding between the enzyme and substrate and increasing in the rate of reaction is possible. Fig.(1) without and with extract respectively made clear obeys Michalis-Menton equation in the present study, that catalase reaction rate could be determined by Michalis-Menton equation; therefore could be calculated, $V_{\circ}=1 / 2 \mathrm{Vmax}$ holds for all enzymes that follow MichalisMenton kinetics, [17]; and (Km, Vmax) calculated from two diagrams MichalisMenton kinetics and Lineweaver-Burk plot that demonstrated in Fig.(1) and Fig.(2) that showed these values in Table (1).

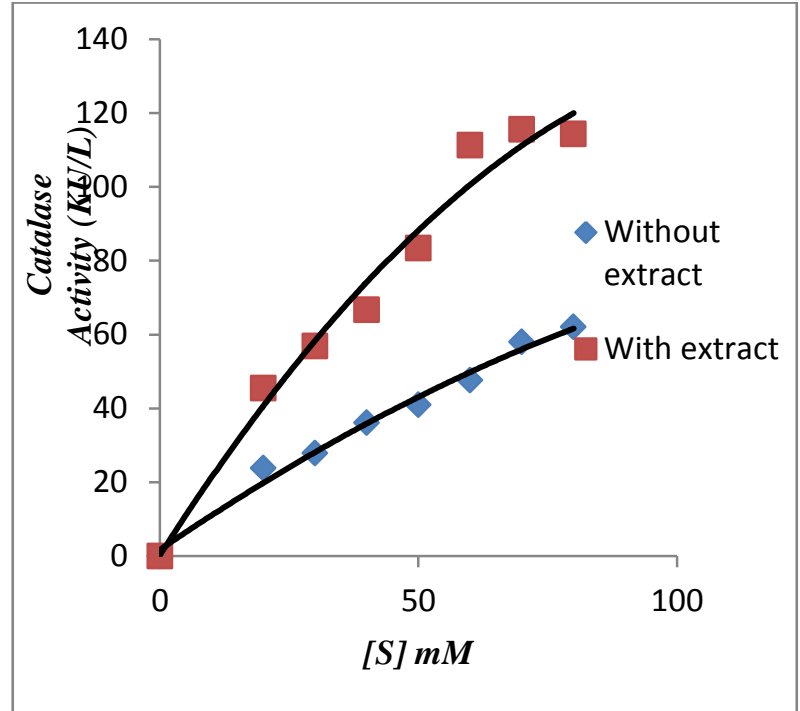

Fig.(1): Catalase enzymatic activity as a function of different substrate $\left(\mathrm{H}_{2} \mathrm{O}_{2}\right)$ concentrations in absence, and in the presence of $(100 \mu l)$ ethanolic extract.

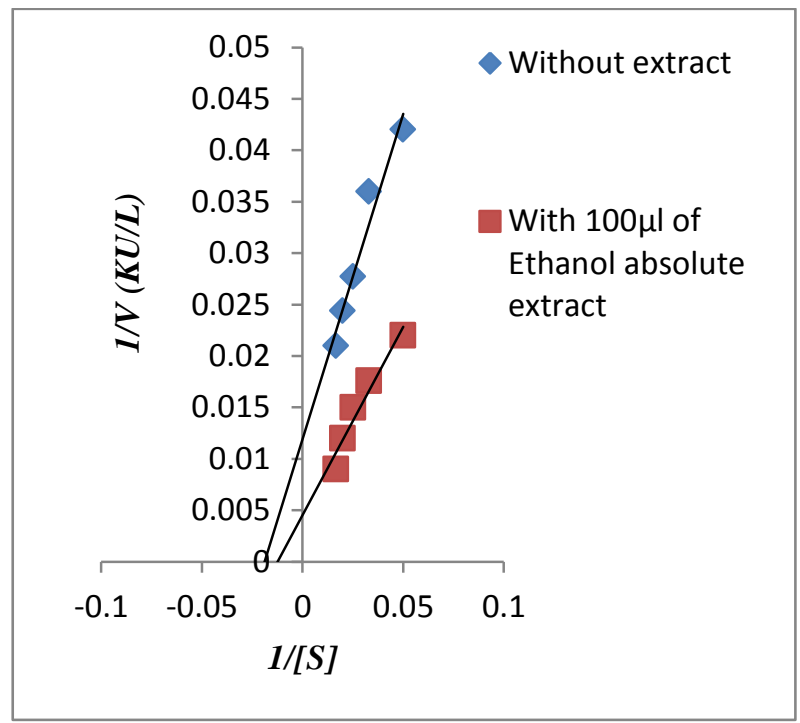

Fig.(2): Lineweaver-Burk plots of catalase with and without extract. 
Table (1)

Kinetic properties of catalase without and with alcoholic extract.

\begin{tabular}{||c||c||c|c|c||c||c|}
\hline \multirow{2}{*}{$\begin{array}{c}\text { Statistical } \\
\text { value }\end{array}$} & \multicolumn{2}{|c|}{ Km (mM) } & \multicolumn{2}{|c|}{$\mathrm{V}_{\max }$ (KU/L) } & \multicolumn{2}{|c|}{$\mathrm{V}_{\text {. }}(\mathrm{KU} / \mathrm{L})$} \\
\cline { 2 - 7 } & Menton & $\begin{array}{c}\text { Lineweaver- } \\
\text { Burk }\end{array}$ & $\begin{array}{c}\text { Michalis } \\
\text { Menton }\end{array}$ & $\begin{array}{c}\text { Lineweaver- } \\
\text { Burk }\end{array}$ & $\begin{array}{c}\text { Michalis } \\
\text { Menton }\end{array}$ & $\begin{array}{c}\text { Lineweaver- } \\
\text { Burk }\end{array}$ \\
\hline $\begin{array}{c}\text { Without } \\
\text { extract }\end{array}$ & 22 & 53.5 & 47.6 & 88.6 & 23.8 & 44.3 \\
\hline $\begin{array}{c}\text { With } \\
\text { Ethanolic } \\
\text { extract }\end{array}$ & 26 & 72.4 & 114.3 & 208 & 57.15 & 104 \\
\hline
\end{tabular}

Lavender Ethanolic extract when obtained was tested in vitro to calculate catalase activity, was gave clear result as showed in Fig.(1) that manifested increasing effect on catalase reaction rate, when compared of activities without and with that of extract and calculate the activation percentage according to the following equation:-

$\left(\%\right.$ Activation $\left.=100-\frac{\text { activity with extract }}{\text { activity witout extract }} \times 100\right)$.

This activation was represented in Fig.(3) at constant extract volume that equal to $(100 \mu l)$ with different substrate concentrations. Where this activation effect measured by calculate the activity with different volume of extract at constant substrate concentration that equal to (60mM) as showed in Fig.(4).

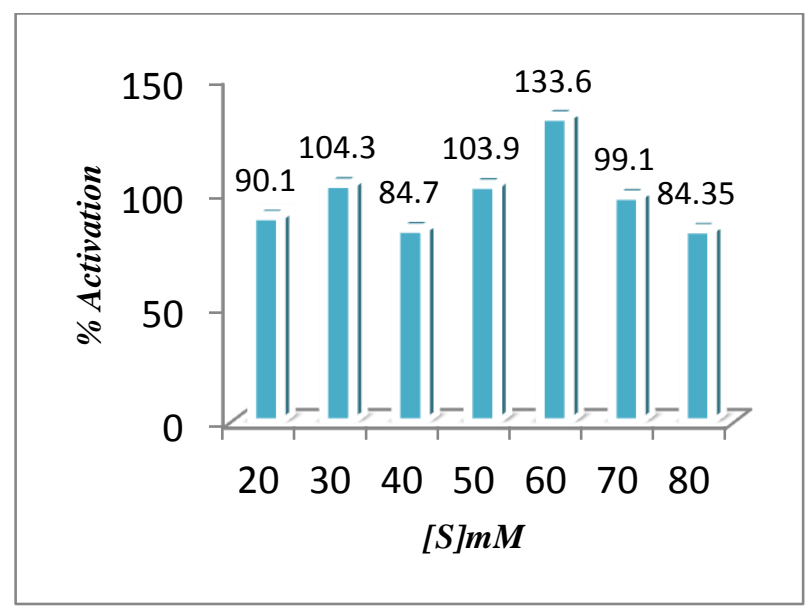

Fig.(3): Activation percentage of catalase with different substrate concentration, at constant Ethanolic extract volume that equal to $(100 \mu l)$.

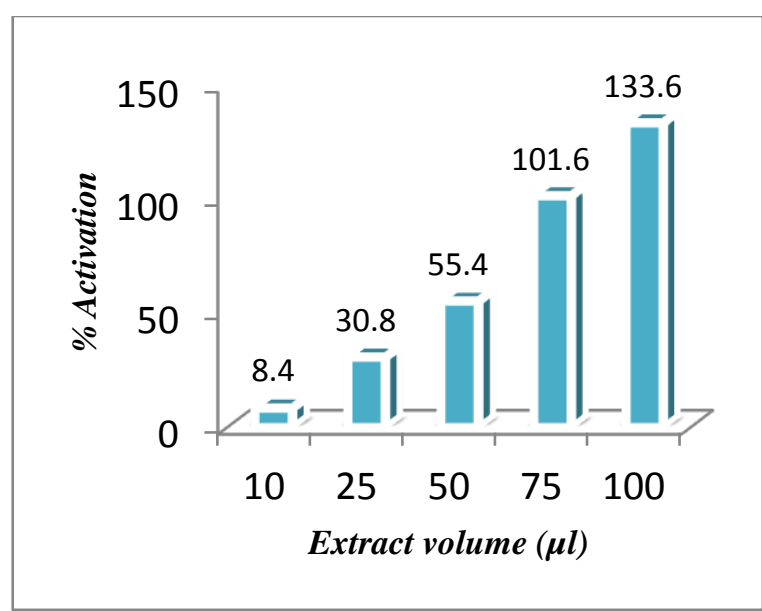

Fig.(4): Activation percentage at constant substrate concentration $(60 \mathrm{mM})$ with different volume of Ethanol absolute extract.

Catalase catalyzes a dual chemical reaction steps the first is $\mathrm{H}_{2} \mathrm{O}_{2}$ decomposition and a second step is oxidation of $\mathrm{H}$ donor, [18]. Else catalyze the oxidation between Hydrogen peroxide and many functional groups as well as (aldehyde, phenols and acids), [19, 8]; therefore the activation by Lavender due to presence one of these compounds as Linalool act as inducer to oxidation reduction process . Reputedly occurs of oxidation reduction between Iron ion and $\mathrm{H}_{2} \mathrm{O}_{2}$; which is located in center of heme group that attached to the enzyme by consume two $\mathrm{H}_{2} \mathrm{O}_{2}$ molecule to produce one oxygen molecule, [19]. Activation action related with oxidation reduction factors; due to bind NADPH as reductant that doesn't directly reduced trapped, but providing highly attractive or reductant, [20]. Then lavender extracted substances by Ethanol absolute preservative on the reducing form of nicotine amide dinucleotide phosphate hydrogen (NADPH) and finally accelerate catalase activity to be activator herbal to catalase in vitro in especially phenols materials 
in lavender play main role in this activation; that improved by some study as well as presence of phenolate ligand coordinate with Tyr558 catalase which could assist to oxidation of iron ion that included in the catalase heme, [19].

Resistance of microorganism to chemotherapy, lead to emphasized on the use of alternative natural product from plant, [1, $21,22]$. Therefore the present study deal with experiment of lavender extract on some isolates microorganisms due to large constituents of this Lavender herbal and antimicrobial action was recorded via this plant. However the biological activity of Lavender was studied in this research by absolute ethanol and hot water extracts; the results of the present study disagreement with that of lavender extracts act as bactericidal against many isolates, [1], other studies was included antibacterial effects results against gram negative and gram positive pet turtleborne pathogenic bacteria and pseudomonas aeroginoesa, [1, 23]. Lavender extracts against isolates with two extracts in the present study manifested have not effect on some of bacteria and fungi, then this study carried out on isolates by incubation with $100 \mu \mathrm{l}$ of two extracts and absolute Ethanol as control for 24 hours, that explained by measurement the diameter of microorganisms inhibition circles zone in disk diffusion test as showed in Table (2) with their pictures in Fig.(5).

Table (2)

Inhibition zone diameter with different extract.

\begin{tabular}{|c|c|c|c|c|}
\hline \multirow{2}{*}{ No } & \multirow{2}{*}{ bacteria species and fungi } & \multicolumn{2}{|c|}{$\begin{array}{c}\text { Inhibition zone }(\mathrm{mm}) \text { with } \\
100 \mu l \text { Ethanolic extract }\end{array}$} & \multirow{2}{*}{ 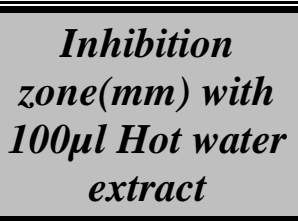 } \\
\hline & & $\begin{array}{c}\text { Test } \\
\text { (Lavender) }\end{array}$ & $\begin{array}{c}\text { Control } \\
\text { Absolute ethanol } \\
\end{array}$ & \\
\hline$\overline{1}$ & Streptococcus Sp & 10 & 10 & \begin{tabular}{c|}
---- \\
\end{tabular} \\
\hline 2 & Bacilli & 13 & 12 & $\begin{array}{l}--- \\
\end{array}$ \\
\hline 3 & Salmonella Typhi & 10 & 10 & 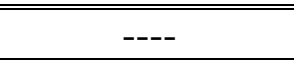 \\
\hline 4 & Shegella & 9 & 9 & $\begin{array}{ll}---- \\
\end{array}$ \\
\hline$\overline{5}$ & Candida albicans & 13 & 12 & $\begin{array}{ll}--- \\
-1\end{array}$ \\
\hline
\end{tabular}
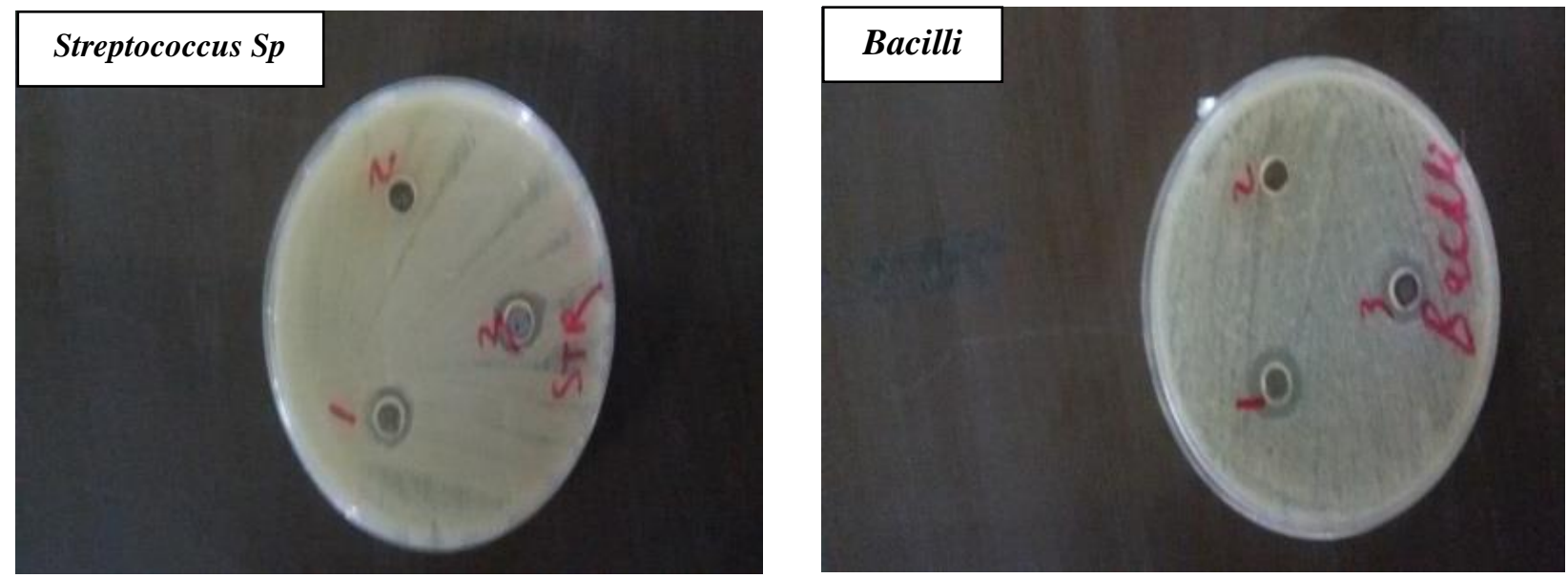

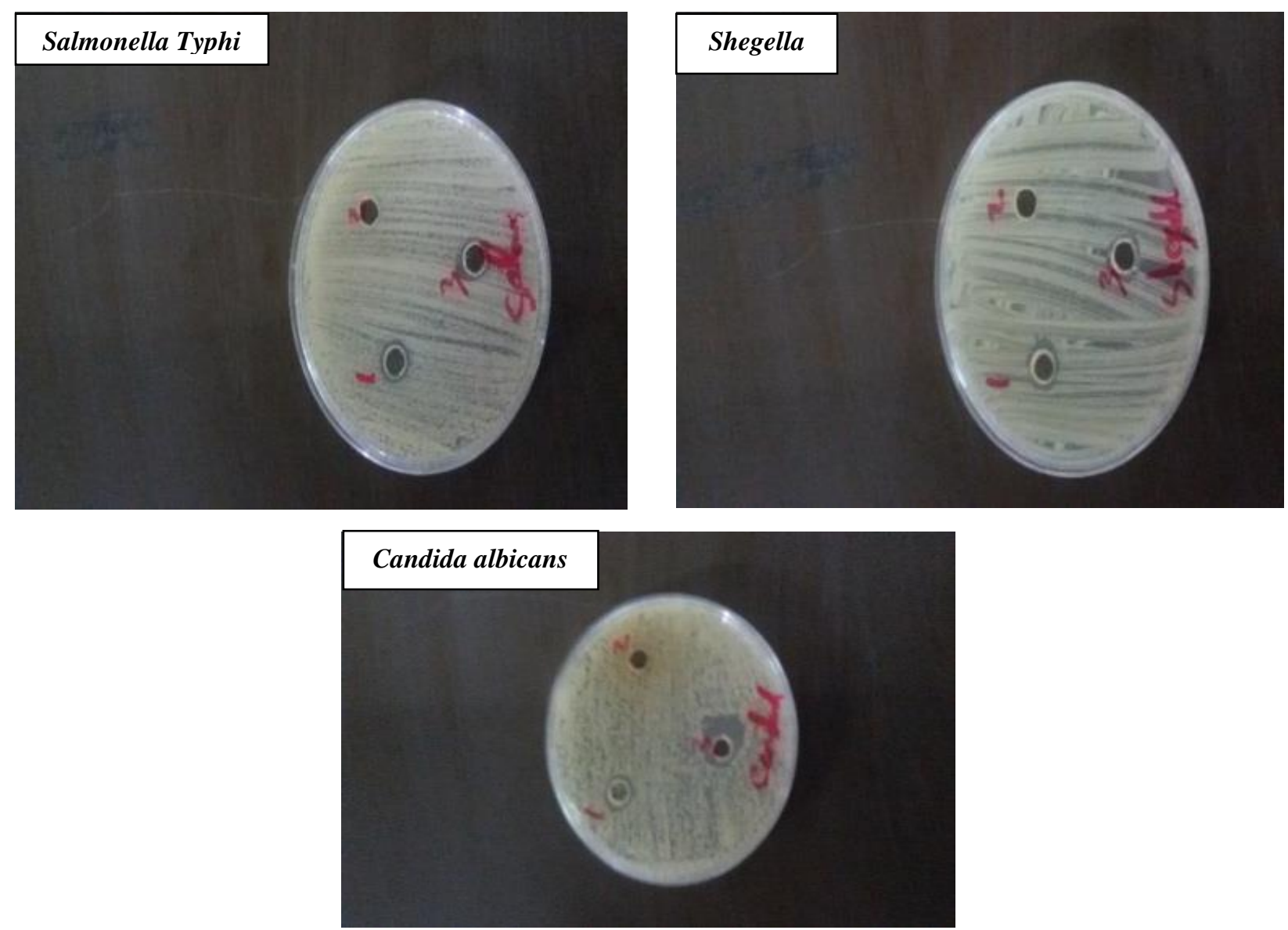

Fig.(5): Antibacterial and anti fungal activities with 100 diffusion disk refers to: (1) is an Ethanolic extract, (2) is an absolute Ethanol as control and (3) is a hot water extract.

The major phenolic compounds that included in Lavender plant vary with varying of origin; this clear in previous study lavender containing on $(51.9 \%)$ Linalool in Bulgarian origin was have more biological activity in compared with that of French origin which containing on (43.2\%) Linalool, [24]. Therefore the resistance of microorganism to lavender extracts in this work may be belonged to the smallest phenolic compounds that affected on the isolates which are dependent on the origin of lavender plant. And finally occur in many microorganisms have been a mechanism and porine related inhibition that protecting bacteria against lavender extracts and result in impervious to phenolic compounds, [25].

\section{Conclusion}

The results that obtained in the present study about Lavender and according the different concentrations of extracts have been effectiveness on the microorganisms and enzymatic activities with different solvents using will be give variable effects. Then we can be getting new information about the effects range of Lavender when preparation this herb with different conditions.

\section{References}

[1] Sabrina H., Honghoi H., Silva B., Wimalasena S., Pathirana H., and Gang J., "Antibacterial activity of essential oil from lavender (Lavandula angostifolia) against pet turtle-borne pathogenic bacteria", Lab Anim Res, 33(3), 195-201, 2017.

[2] Garikapati D., Kiran B., Aarti S \& Bikram, S., "Volatile composition of Lavandula angostifolia produced by different extraction techniques", Journal of Essential Oil research, 28(6), 107-110, 2016.

[3] Gabriel F., Saulo E \& Expedito L., "Effect of Lavender (Lavandula angostifolia) essential oil on acute inflammatory response", Evidence-Based complementary and Alternative Medicine, 10 pages, 2018.

[4] Jivad N., Rabiei Z., "A review study on medicinal plants used in the treatment of learning and memory impairments", Asian Pac J Trop Biomed, 4, 780-789, 2014. 
[5] Cavanagh H M., Wilkinson J M., "Biological activities of lavender essential oil", Phytother Res, 16(4), 301-308, 2002.

[6] Lis-Balchin M., Hart S., "Studies on the mode of action of the essential oil of lavender (Lavandula angustifolia $P$. Miller)", Phytother Res, 13(6), 540-542, 1999.

[7] Yunanto A., Gunawan P., Iskandar I \& Suhartono E., "Effect of Antibitiotic Applications on Salivary Amylase and Catalase Kinetic Parameters on Neonatal at Risk of Sepsis In Vitro", International Journal of Toxicological and Pharmacological Research, 7(6), 269-273, 2015.

[8] Chelikani P., Fita I., Loewen P C., "Diversity of structures and properties among catalases", Cellular and Molecular Life Sciences, 61(2): 192-208, 2004.

[9] Gouet P., Jouve H M \& Dideberg O., "Crystal structure of Proteus mirabilis PR catalase with and without bound NADPH", J. Mol. Biol, 249: 933-954, 1995.

[10] Shan W., Guolin H., Meng C., Tao Z., Wenming $X \&$ Xinghul L., "The role of antioxidant enzymes in the ovaries", Oxidative Medicine and Cellular Longevity, 14 pages, 2017; 2017.

[11] Goodsell D S., ""Catalase", Molecule of the Month. RCSB Protein Data Bank", Retrieved, 08-23, (2016).

[12] Goth L., Meszaros I \& Nemeth H., "Serum catalase enzyme activity in liver diseases", Acta biologica Hungarica, 38(2), 287-290, 1986.

[13] Mahmoud H \& Hussien N., "Data supporting the spectrophotometric method for the estimation of catalase activity", 6, 194-199, 2016.

[14] Bisignano G., Tomaino A., Cascio RG., Lo Crisafi., Uccella N., and Saija A.,"On the In-vitro Antimicrobial Activity of Oleuropein and Hydroxytyrosol", Journal of Pharmacy and Pharmacology, 51, 971-974, 2005.

[15] Fratianni F., Tucci M., Palma D C., Pepe R \& Nazzaro F., "Polyphenolic composition in different parts of some cultivars of globe artichoke for some Bactria", Food Chemistry, 104, 1282-1286, 2007.
[16] Devlin T M., "Text Book of Biochemistry with clinical correlations", $7^{\text {th }}$ edition, A john wiley and sons, Inc publications, USA, 2015.

[17] Lehninger., "Principles of Biochemistry", $7^{\text {th }}$ Edition, 256, 2016.

[18] Hugo A., "Catalase in vitro. Methods in Enzymology", 1113, (142-154), 2016.

[19] Boon E M., Downs A and Marcey D., "Proposed Mechanism of Catalase". Catalase: $\mathrm{H}_{2} \mathrm{O}_{2}: \quad \mathrm{H}_{2} \mathrm{O}_{2}$ Oxidoreductase: Catalase Structural Tutorial", Retrieved, 0211, 2007.

[20] Kirkman H N., Rolfo M., Ferraris A M and Gaetani G F., "Mechanisms of protection of catalase by NADPH", J. Biol. Chem, 274 13908-13914, 1999.

[21] Prabuseenivasan S., Jayakumar M., Ignacimuthu S., "In vitro antibacterial activity of some plant essential oils", BMC Complement Altern Med, 6, 39, 2006.

[22] O'Bryan C A., Pendleton S J., Crandall P $\mathrm{G}$ and Ricke S C., "Potential of Plant Essential Oils and Their Components in Animal Agriculture-in vitro Studies on Antibacterial Mode of Action", Front Vet Sci, 2, 35, 2015.

[23] Anna M, Ramona B., Erika C., Ilky E., Maria D \& Seyed F., "Antimicrobial activity of eugenol and essential oils containing eugenol: A mechanistic viewpoint", Critical Reviews in Microbiology, 43(6), 2017.

[24] Lis-Balchin M., Deans S G and Eaglesgam E., "Relationship between bioactivity and chemical composition of commercial essential oils", Flavour Fragr J, 13(2): 98-104, 1998.

[25] Longbottom C J., Carson C F., Hammer K A., Mee B J., Riley T V., "Tolerance of Pseudomonas aeruginosa to Melaleuca alternifolia (tea tree) oil is associated with the outer membrane and energy-dependent cellular processes", J Antimicrob Chemother, 54(2): 386-392, 2004. 